\title{
Menstrual cyclicity of finger joint size and grip strength in patients with rheumatoid arthritis
}

\author{
S. R. RUDGE, ${ }^{1}$ I. C. KOWANKO, ${ }^{1}$ A ND P. L. D RURY ${ }^{2}$ \\ From the ${ }^{1}$ Department of Rheumatology, City Hospital, Nottingham, and the ${ }^{2}$ Department of Endocrinology, St \\ Bartholomew's Hospital, London
}

SUMMARY Daily measurements of finger joint size, grip strength, and body weight have been made throughout 2 complete menstrual cycles in 7 female patients with rheumatoid arthritis and 6 healthy female controls. Sine wave analysis showed significant individual cyclical rhythms $(\mathrm{p}<0.05)$ for finger joint size ( 5 patients, 4 controls), nude weight ( 5 patients, 3 controls), and grip strength (4 patients, 3 controls). In addition analysis of group data, on the assumption of a 28-day cycle, showed a significant cycle for grip strength in the rheumatoid patients, with a nadir at 28 days. In the normal subjects much of the cyclical variation in finger joint size could be explained by changes in weight (median $49.5 \%$ ), but this was not so in patients with rheumatoid arthritis (median $2 \cdot 8 \%$ ). These findings suggest the existence of a cyclical variation in disease activity in rheumatoid arthritis.

We have noted that a number of young women with rheumatoid arthritis (RA) complain of an exacerbation of symptoms just before or at the time of menstruation. Such complaints are commonly attributed to an alteration in mood or pain perception occurring as part of the 'premenstrual tension syndrome'. ${ }^{1}$ We have studied a number of female patients with RA to establish whether objective measures of disease activity such as finger joint size (FJS) and grip strength can be shown to alter during different phases of the menstrual cycle.

\section{Patients and methods}

Seven consecutive female patients attending Nottingham City Hospital Outpatient Department with definite or classical RA (according to ARA criteria $^{2}$ ) were studied irrespective of whether they experienced premenstrual exacerbation of their symptoms. All were aged between 18 and 45 years (mean 34, SD 4) and all were having regular menstrual cycles (between 24 and 32 days prior to the study). None were receiving steroids, oral contraceptives, or diuretics, and none changed their antiinflammatory medication either during or in the month before the study. All were shown to be ovulat-

Accepted for publication 10 June 1982.

Correspondence to Dr S. R. Rudge, City Hospital, Hucknall Road, Nottingham NG5 1PB. ing at the time of study as defined by a luteal phase serum progesterone $\geqslant 15 \mathrm{nmol} / \mathrm{l}$. Six healthy female controls (mean age 31 , SD 9 years) fulfilling the same criteria for age and regularity of cycles were also studied: none was on any medication.

Each subject was asked to make daily measurements of nude body weight, FJS, and grip strength between 0700 and 1000 hours each morning throughout 2 complete menstrual cycles. Nude weight was recorded to the nearest $0.5 \mathrm{~kg}$ on domestic scales, the calibration of which was not altered during the study. Subjects were taught to make their own measurements of FJS (for the proximal interphalangeal joints of the fingers and distal interphalangeal joints of the thumb) with a metal spring gauge (Roussell), and the results were expressed as the sum of the 10 digits in mm. Grip strength was measured for each hand with an Accoson blood pressure cuff (Boots) and recorded to the nearest 5 $\mathrm{mmHg}$. Subjects were asked to record the days on which menstruation occurred.

Data analysis. The data were analysed by standard statistical techniques (as indicated) and also by the single and group mean cosinar analysis developed by Halberg, Tong, and Johnson. ${ }^{3}$ This involves the fitting of a sine wave with a chosen time period (in this case either the length of the individual's menstrual cycle or an assumed cycle length of 28 days) to the observed data. The 3 parameters used for analysis were the mean level of the sine wave (mesor), its 
amplitude (peak to trough), and the timing of the peak of the curve (acrophase), timed from the onset of menstruation (day 0). This form of analysis is subsequently referred to as computerised sine wave analysis.

\section{Results}

IN DIVIDUAL ANALYS IS

Individual cycle lengths for the observed cycles in the 13 subjects varied from 21 to 35 days. Table 1 shows the means and variation of FJS, body weight, and grip strength occurring in the rheumatoid and control subjects together with the timing of the peaks. Table 2 shows by means of computerised sine wave analysis that of the 7 patients with RA 6 showed significant cycles for body weight $(p<0.05), 4$ for FJS ( $p<0.01)$, and 4 for grip strength $(p<0 \cdot 05)$. The corresponding data for the 6 control subjects show 4,3 , and 2 significant cycles respectively.

Figure $1 \mathrm{a}$ is a graphical representation of the daily measurements recorded by one patient with RA over the course of 2 menstrual cycles. Weight and FJS increased and grip strength decreased at menstruation. This pattern was repeated during the second cycle. Figure $1 \mathrm{~b}$ shows the same data with a sine wave corresponding to the patient's own cycle length (28 days) superimposed. Computerised sine wave analysis showed the weight and grip strength cycles to be significant $(p<0.001$ and $p<0.05$ respectively).

\section{GROUP ANALYSIS}

Analysing the patients with RA and controls in separate groups and assuming a 28-day cycle we obtained a significant. rhythm for grip strength in the patients with RA ( $<<0.05)$ with a peak at 14.3 days (Fig. 2).

Table 1 Variations in finger joint size, body weight, and grip strength in patients with rheumatoid arthritis and controls during 2 menstrual cycles

\begin{tabular}{|c|c|c|c|c|c|c|c|c|c|c|}
\hline \multirow[t]{2}{*}{ Subject } & \multirow{2}{*}{$\begin{array}{l}\text { Cycle length } \\
\text { (days) }\end{array}$} & \multicolumn{3}{|c|}{ Finger joint size } & \multicolumn{3}{|l|}{ Weight } & \multicolumn{3}{|c|}{ Mean grip strength } \\
\hline & & $\begin{array}{l}\text { Mean } \\
(\mathrm{mm})\end{array}$ & $\begin{array}{l}\text { Variation } \\
(\mathrm{mm})\end{array}$ & $\begin{array}{l}\text { Peak times } \\
\text { (day) }\end{array}$ & $\begin{array}{l}\text { Mean } \\
(\mathrm{kg})\end{array}$ & $\begin{array}{l}\text { Variation } \\
(\mathrm{kg})\end{array}$ & $\begin{array}{l}\text { Peak times } \\
\text { (day) }\end{array}$ & $\begin{array}{l}\text { Mean } \\
(\mathrm{mmHg})\end{array}$ & $\begin{array}{l}\text { Variation } \\
(\mathrm{mmHg})\end{array}$ & $\begin{array}{l}\text { Peak times } \\
\text { (day) }\end{array}$ \\
\hline \multicolumn{11}{|c|}{ Rheumatoid arthritis } \\
\hline 1 & 28 & 555 & $11(1 \cdot 2 \%)$ & $\frac{7}{6}$ & $68 \cdot 5$ & $2 \cdot 0(2 \cdot 9 \%)$ & $\frac{27}{27}$ & 97 & $25(26 \%)$ & $\frac{13}{21}$ \\
\hline 2 & 26 & 483 & $18(3 \cdot 7 \%)$ & $\frac{24}{17}$ & $49 \cdot 1$ & $2 \cdot 5(5 \cdot 1 \%)$ & $\frac{3}{5}$ & 84 & $75(89 \%)$ & $\frac{11}{10}$ \\
\hline 3 & 27 & 606 & $22(3 \cdot 6 \%)$ & 26 & $59 \cdot 5$ & $2 \cdot 0(3 \cdot 4 \%)$ & 1 & 102 & $80(78 \%)$ & 24 \\
\hline 4 & 34 & 536 & $23(4 \cdot 3 \%)$ & 32 & $58 \cdot 3$ & $3 \cdot 5(6 \cdot 0 \%)$ & 33 & 195 & $65(33 \%)$ & 12 \\
\hline 5 & 28 & 519 & $31(6 \cdot 0 \%)$ & $\frac{5}{5}$ & $57 \cdot 7$ & $3 \cdot 0(5 \cdot 2 \%)$ & $\frac{6}{5}$ & 276 & $90(33 \%)$ & $\frac{15}{18}$ \\
\hline 6 & 35 & 579 & $86(14 \cdot 8 \%)$ & 33 & $66 \cdot 8$ & $0.5(0.7 \%)$ & 34 & 103 & $36(35 \%)$ & 17 \\
\hline 7 & 26 & 501 & $7(1.4 \%)$ & 21 & $58 \cdot 4$ & $1.0(1.8 \%)$ & 18 & 115 & $20(17 \%)$ & 10 \\
\hline \multicolumn{11}{|l|}{ Controls } \\
\hline 8 & 28 & 482 & $41(8 \cdot 5 \%)$ & $\frac{27}{5}$ & 70 & $4 \cdot 0(5 \cdot 7 \%)$ & $\frac{1}{5}$ & 136 & $130(95 \%)$ & $\frac{9}{20}$ \\
\hline 9 & 24 & 472 & $35(7 \cdot 4 \%)$ & $\frac{4}{22}$ & 57 & $1 \cdot 5(2 \cdot 6 \%)$ & $\frac{5}{3}$ & 279 & $70(25 \%)$ & $\frac{14}{7}$ \\
\hline 10 & 21 & 471 & $14(3 \cdot 0 \%)$ & $\frac{1}{19}$ & 58 & $5 \cdot 0(8 \cdot 6 \%)$ & $\frac{1}{*}$ & 296 & $80(27 \%)$ & $\frac{*}{*}$ \\
\hline 11 & 25 & 474 & $16(3 \cdot 4 \%)$ & 1 & 63 & $3 \cdot 5(5 \cdot 5 \%)$ & 11 & 265 & $50(19 \%)$ & 24 \\
\hline 12 & 27 & 547 & $18(3 \cdot 3 \%)$ & $\frac{12}{3}$ & 50 & $1 \cdot 0(2 \cdot 0 \%)$ & $\frac{25}{3,17,23}$ & 243 & $75(31 \%)$ & $\frac{16}{15}$ \\
\hline 13 & 29 & 442 & $22(5.0 \%)$ & 1 & 54 & $1.5(2 \cdot 7 \%)$ & 1 & 298 & $19(6 \%)$ & $\stackrel{*}{*}$ \\
\hline
\end{tabular}

Variation $=$ maximum - minimum (percentage of mean in brackets).

Peak times = days on which peak values were recorded in each cycle.

*Multiple similar values over entire cycle.

The short rules between some peak times separate the 2 values obtained during 2 different menstrual cycles. 
Menstrual cyclicity of finger joint size and grip strength

Table 2 Computerised sine wave analysis based on individual cycles in patients with rheumatoid arthritis and controls

\begin{tabular}{|c|c|c|c|c|c|c|c|c|c|c|c|c|c|}
\hline \multirow[t]{2}{*}{ Subject } & \multirow{2}{*}{$\begin{array}{l}\text { Cycle } \\
\text { length } \\
\text { (days) }\end{array}$} & \multicolumn{4}{|c|}{ Finger joint size } & \multicolumn{4}{|l|}{ Weight } & \multicolumn{4}{|c|}{ Mean grip strength } \\
\hline & & $\begin{array}{l}\text { Mesor } \\
(\mathrm{mm})\end{array}$ & $\begin{array}{l}\text { Acro } \\
\text { (days) }\end{array}$ & $\begin{array}{l}\text { Ampli } \\
(\mathrm{mm})\end{array}$ & $p$ & $\begin{array}{l}\text { Mesor } \\
(\mathrm{kg})\end{array}$ & $\begin{array}{l}\text { Acro } \\
\text { (days) }\end{array}$ & $\begin{array}{l}\text { Ampli } \\
(\mathrm{kg})\end{array}$ & $p$ & $\begin{array}{l}\text { Mesor } \\
(\mathrm{mmHg})\end{array}$ & $\begin{array}{l}\text { Acro } \\
\text { (days) }\end{array}$ & $\begin{array}{l}\text { Ampli } \\
(\mathbf{m m H g})\end{array}$ & $p$ \\
\hline \multicolumn{14}{|c|}{ Rheumatoid arthritis } \\
\hline 1 & 28 & 555 & $3 \cdot 2$ & $1 \cdot 0$ & $0 \cdot 144$ & $68 \cdot 5$ & $3 \cdot 4$ & $0 \cdot 4$ & 0.001 & 97 & $12 \cdot 8$ & $2 \cdot 7$ & 0.029 \\
\hline$* 2$ & 26 & 483 & $20 \cdot 5$ & $2 \cdot 7$ & 0.001 & $49 \cdot 1$ & $7 \cdot 1$ & $0 \cdot 4$ & 0.012 & 84 & $12 \cdot 8$ & $3 \cdot 7$ & $0 \cdot 166$ \\
\hline 3 & 27 & 606 & $26 \cdot 7$ & $2 \cdot 8$ & $0 \cdot 133$ & $59 \cdot 5$ & $3 \cdot 8$ & $0 \cdot 3$ & 0.036 & 102 & $10 \cdot 4$ & $5 \cdot 1$ & 0.521 \\
\hline 4 & 34 & 536 & $30 \cdot 6$ & $4 \cdot 0$ & 0.001 & $58 \cdot 3$ & $30 \cdot 8$ & $0 \cdot 6$ & 0.003 & 195 & $13 \cdot 1$ & $9 \cdot 0$ & 0.004 \\
\hline *5 & 28 & 519 & $4 \cdot 8$ & $3 \cdot 8$ & 0.010 & $57 \cdot 7$ & $5 \cdot 5$ & 0.7 & 0.001 & 276 & $18 \cdot 7$ & $14 \cdot 5$ & 0.029 \\
\hline 6 & 35 & 579 & $31 \cdot 6$ & $12 \cdot 9$ & $0 \cdot 115$ & $66 \cdot 8$ & $27 \cdot 6$ & 0.4 & 0.001 & 103 & $12 \cdot 1$ & $6 \cdot 2$ & 0.017 \\
\hline$* 7$ & 26 & 501 & $20 \cdot 1$ & $1 \cdot 2$ & 0.001 & $58 \cdot 4$ & $11 \cdot 4$ & $0 \cdot 1$ & 0.901 & 115 & $8 \cdot 4$ & $1 \cdot 0$ & 0.447 \\
\hline \multicolumn{14}{|l|}{ Control } \\
\hline$* 8$ & 28 & 482 & $9 \cdot 9$ & $4 \cdot 3$ & 0.043 & 70 & $11 \cdot 4$ & $0 \cdot 7$ & 0.002 & 136 & $25 \cdot 2$ & $16 \cdot 6$ & 0.018 \\
\hline 9 & 24 & 472 & $1 \cdot 6$ & $1 \cdot 3$ & 0.723 & 57 & $3 \cdot 1$ & 0.4 & 0.001 & 279 & 14 & $2 \cdot 0$ & 0.749 \\
\hline${ }^{*} 10$ & 21 & 471 & $20 \cdot 8$ & $0 \cdot 8$ & 0.415 & 58 & $20 \cdot 0$ & 0.4 & 0.060 & 296 & $6 \cdot 7$ & $5 \cdot 1$ & $0 \cdot 110$ \\
\hline${ }^{*} 11$ & 25 & 474 & $9 \cdot 5$ & 0.9 & 0.450 & 63 & $17 \cdot 0$ & $0 \cdot 5$ & 0.048 & 265 & $2 \cdot 9$ & $7 \cdot 2$ & 0.026 \\
\hline${ }^{*} 12$ & 27 & 547 & $26 \cdot 1$ & $3 \cdot 3$ & 0.001 & 50 & $24 \cdot 4$ & $0 \cdot 1$ & 0.099 & 243 & $13 \cdot 8$ & $3 \cdot 2$ & $0 \cdot 660$ \\
\hline${ }^{*} 13$ & 29 & 442 & $12 \cdot 6$ & $4 \cdot 9$ & 0.009 & 54 & $12 \cdot 6$ & 0.6 & 0.018 & 298 & $27 \cdot 9$ & $2 \cdot 2$ & 0.054 \\
\hline
\end{tabular}

Acro $=$ acrophase (days after onset of menstruation).

Ampli = Amplitude (mm).

$\mathrm{p}=$ significance.

*Subject showed a significant correlation $(\mathrm{p}<0.02)$ between finger joint size and weight.
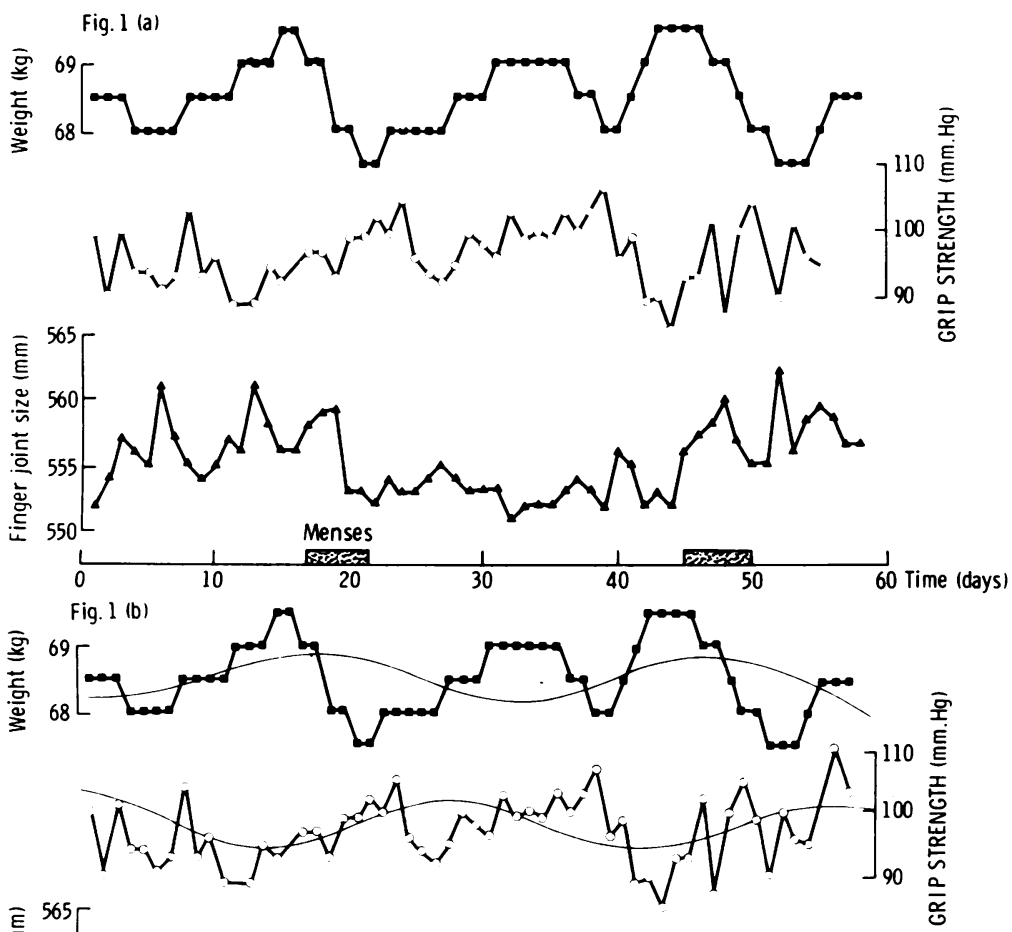

Fig. 1 (a) Daily values for weight, grip strength, and finger joint size recorded by a patient with $R A$ during 2 menstrual cycles. (b) Sine waves corresponding to the patient's own cycle length ( 28 days) superimposed on the data in (a).

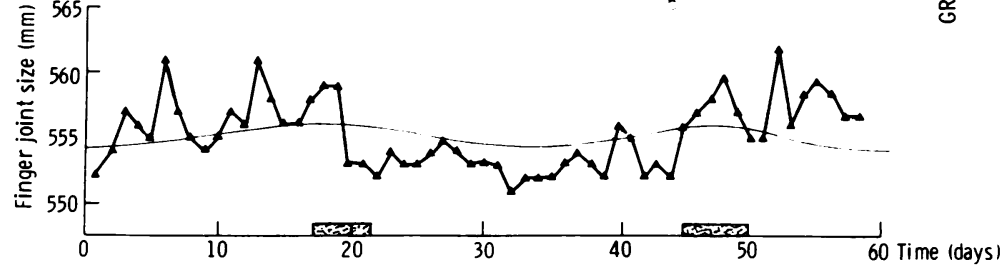




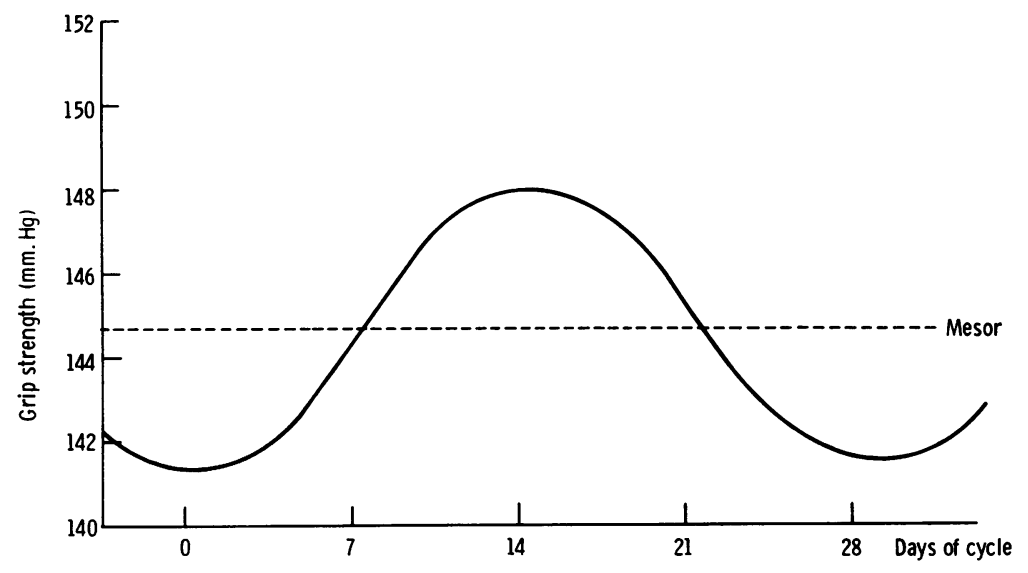

Fig. 2 Twenty-eight day group rhythm for grip strength in 7 patients with $R A$.
Table 3 Percentage of variation in FJS explained by weight change

\begin{tabular}{lcc}
\hline Group & $\begin{array}{c}\text { Rheumatoid } \\
(n=7)\end{array}$ & $\begin{array}{c}\text { Control } \\
(n=6)\end{array}$ \\
\hline \% FJS variation explained & $11 \cdot 6 \%$ & $46 \cdot 1 \%$ \\
by body weight change $\left(\mathrm{r}^{2}\right)$ & $0 \cdot 7 \%$ & $22 \cdot 4 \%$ \\
& $0 \cdot 4 \%$ & $70 \cdot 6 \%$ \\
& $0 \cdot 0 \%$ & $88.4 \%$ \\
& $16 \cdot 7 \%$ & $1 \cdot 7 \%$ \\
& $16.2 \%$ & $53 \cdot 1 \%$ \\
& $2 \cdot 8 \%$ & \\
\hline Median & $2 \cdot 8 \%$ & $49 \cdot 5 \%$ \\
\hline
\end{tabular}

$\mathrm{p}<0.01$ (Wilcoxon).

None of the other group rhythms achieved statistical significance.

\section{RELATIONSHIP BETWEEN FJS AND BODY} WEIGHT (Table 3)

We have previously described a linear correlation between FJS and change in body weight. ${ }^{4}$ In this study 3 of the 7 patients with RA and 5 of 6 controls showed such a correlation ( $p<0.02$ for each). Table 3 shows the percentage of variation in FJS $\left(r^{2}\right)$ which can be explained by changes in body weight alone. In the control group the median amounts to $49.5 \%$ compared with only $2 \cdot 8 \%$ in the patients with RA ( $p<0.01$ by Wilcoxon rank sum test).

\section{Discussion}

Circatrigintan (30-day) rhythms thought to be related to the hormonal changes occurring during a normal menstrual cycle have been described in many branches of medicine. These include changes in optical and auditory perception, ${ }^{5}$ body weight $^{6}{ }^{6}$ and blood pressure ${ }^{7}$ as well as the disturbances in mood and behaviour which have recently gained widespread publicity. ${ }^{8}$ Clinical observation of several patients with apparent severe premenstrual exacerbations of their rheumatoid disease led us to question other women directly: it appears that this phenomenon is not rare. In the present study we have assessed only objective measures of disease activity, since subjective assessments of pain or stiffness may depend on the perceptual variations outlined above.

Most of the patients and controls showed a significant cycle of body weight, with the maximum occurring around the time of menstruation-a finding previously described in normal subjects. ${ }^{6}$ A significant cyclical change in FJS was seen in 4 of 7 patients with RA, with all peaks occurring within 6 days of the start of menstruation. It is interesting to note that, even in the nonsignificant cycles in rheumatoid patients, peak FJS was recorded around the time of menstruation. Significant cycles for grip strength were obtained in 4 of 7 patients with RA, and in 6 of the 7 patients studied the peak occurred at mid cycle. This closely corresponds with the results of group analysis of rheumatoid patients, in whom a significant cycle for grip strength was observed with a peak at 14.3 days. Thus we have demonstrated menstrual cyclicity in both FJS and grip strength and have shown that peak values for these parameters occur at menstruation and mid cycle respectively, suggesting an inverse relationship. To our knowledge such menstrual cyclicity has not been previously reported.

The reproducibility of grip strength and FJS measurements has been well demonstrated provided they are undertaken by the same individual at the same time of day. ${ }^{910}$ Recent work from our unit has confirmed that such measurements can be successfully undertaken by patients in their own homes. ${ }^{11}$ This and another recent study ${ }^{12}$ have confirmed the 
marked circadian variations in both these parameters. In retrospect it is therefore possible that by allowing our subjects a period of up to 3 hours in which to make measurements we may have obscured some menstrual or other variations.

Our method of statistical analysis will also tend to underestimate the amplitude of any cyclical variation where this is not of sine wave form, for example, hormonal concentrations (Fig. 3) ${ }^{13}$ In addition there are clear problems of fitting sine waves to cycles of varying lengths where one part of the cycle (the luteal phase) remains almost constant at 14 days. The further the actual cycle length varies from 28 days, the less well will a sine curve fit. In view of this we have also presented the raw data in Table 1 to demonstrate the magnitude of the variations obtained. Differences in total FJS of only $4 \mathrm{~mm}$ have been regarded as clinically significant in some drug trials. ${ }^{14}$ Figures greater than this were obtained in all subjects during the menstrual cycle, with variations as great as $86 \mathrm{~mm}$ being recorded. Variations of even greater proportion seen in grip strength would suggest that our findings are of clinical relevance in a significant number of patients, as further evidenced by our patients' own observations.

We have previously described a linear correlation between FJS and minor changes in body weight. ${ }^{4}$ This was confirmed in 8 of the 13 subjects in the present study, raising the possibility that the observed cyclical changes in joint size were a reflection of weight change rather than alterations in disease activity. However, calculation of the percentage variation in joint size which could be explained by change in weight revealed a large discrepancy between the rheumatoid and control groups (3\% compared with $50 \%)$. This, together with the reciprocal cyclicity in grip strength seen in the rheumatoid patients, strongly suggests that our results indicate changing disease activity during the menstrual cycle.

The mechanism of such cyclicity of disease activity is not immediately apparent. Circadian variations in the immune response have been well described, ${ }^{15}$ and recently attempts have been made to relate these to circadian variations in disease activity in rheumatoid arthritis. Harkness et al..$^{12}$ observed significant variations in peripheral blood neutrophil counts, immune complexes (as measured by Clq binding activity), and plasma cortisol levels in patients with RA during the 24 hours. Since corticosteroids are known to affect immune processes in many ways, ${ }^{16}$ they and others ${ }^{17}$ have suggested that such variations in the inflammatory process may result from the circadian variations of plasma corticosteroid levels. Menstrual cyclicity in the immune response has also been reported. Several authors have described cyclical changes in local antibody release, ${ }^{18}{ }^{19}$ and Mathur et al.$^{20}$ have recently shown cyclic variations in white cell subpopulations during the normal menstrual cycle in women. Monocyte and granulocyte counts were significantly higher in the luteal than the follicular phase, and lymphocyte counts reached a minimum at mid cycle. They related these findings to the fluctuations of oestrogen and progesterone seen during the normal cycle.

Much interest has recently been expressed in the possible role of these sex / hormones' as inhibitors; of inflammatory and immune responses in pregnancy. ${ }^{21}$ Although some studies have demonstrated inhibitory effects of both oestrogen and progesterone on various components of the immune response in vitro, ${ }^{22}{ }^{23}$ it is questionable whether either plays an important role in vivo. It should also be remembered that the levels of both hormones are much higher in preg-

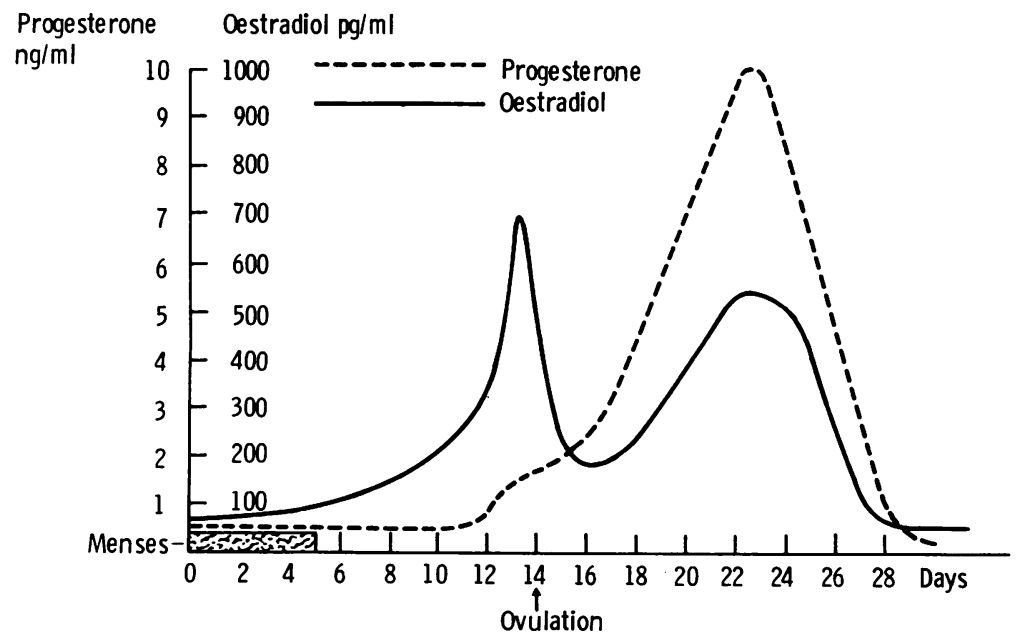

Fig. 3 Hormonal changes in the normal menstrual cycle (Speroff et al. ${ }^{13}$ ). 
nancy and that oestrogen is largely in the form of oestriol rather than oestradiol. Some of the various pregnancy-associated proteins also implicated in the pregnancy remission experienced by many women with RA are also present at a low level in the nonpregnant state, but so far studies have not revealed any significant menstrual cyclicity. ${ }^{24}$

Our results demonstrate the existence of a menstrual cyclicity in objective signs of RA and strongly suggest that this relates to variations in disease activity. They thereby introduce a further variable which requires consideration whenever disease activity in females is assessed. This applies particularly to clinical drug trials, which commonly involve young women but rarely employ observation periods in multiples of 4 weeks. While the underlying mechanism for these fluctuations remains unknown, it is of great value for the patient to be aware of such endogenous variations in disease activity, since it may allow her management to be modified accordingly.

The authors thank Dr A. J. Swannell and Dr D. H. Bossingham for allowing us to study their patients, Dr L. Perry for expert technical assistance, and Miss Mary Gillingham for typing the script.

\section{References}

1 Steiner M, Haskett R F, Carroll R J. Premenstrual tension syndrome. Acta Psychiatr Scand 1980; 62: 177-90.

2 Ropes M W, Bennett F A, Cobb S, Jacox R, Jessar R A. Revision of diagnostic criteria for rheumatoid arthritis. Bull Rheum Dis 1959; 9: 175-6.

3 Halberg F, Tong Y L, Johnson E A. Circadian system phase-an aspect of temporal morphology, procedures and illustrative examples. In: Van Mayersbach $\mathbf{H}$, ed. Cellular aspects of biorhythms. New York: Springer, 1967: 20-48.

4 Rudge S R, Drury P L. Finger joint size measurements and changes in body weight. Lancet 1981; ii: 877-8.

5 Henkin R I. Sensory changes during the menstrual cycle. In: Ferin M, Halberg F, Richart $\mathbf{R}$ M, Vande Wiele $\mathbf{R}$ L, eds. Biorhythms and human reproduction. New York: Wiley, 1974: 277-85.

6 Robinson M F, Watson P E. Variations in body weight of young women during the menstrual cycle. Br J Nutr 1965; 19: 237-45.
7 Engel P, Hidebrandt G. Rhythmic variations in reaction time, heart rate and blood presure at different durations of the menstrual cycle. In: Ferin M, Halberg F, Richart R M, Vande Wiele R L, eds. Biorhythms and human reproduction. New York: Wiley, 1974: 325-33.

8 Brahams D. Premenstrual syndrome: a disease of the mind? Lancet 1981; ii: 1238-40.

9 Lee P, Baxter A, Carson Dick W, Webb J. An assessment of grip strength measurement in rheumatoid arthritis. Scand $J$ Rheumatol 1974; 3: 17-23.

10 Webb J, Wilson Downie W, Carson Dick W, Lee P. Evaluation of digital joint circumference measurements in rheumatoid arthritis. Scand J Rheumatol 1973; 2: 127-31.

11 Kowanko I C, Knapp M S, Pownall R, Swannell A J. Domiciliary self-measurement in rheumatoid arthritis and the demonstration of circadian rhythmicity. Ann Rheum Dis 1982; 41: 453-5.

12 Harkness J A L, Richter M B, Panayi G S, et al. Circadian variation in disease activity in rheumatoid arthritis. $\mathrm{Br} \mathrm{Med} J$ 1982 ; i: $551-4$.

13 Speroff L, Vande Wiele R L. Regulation of the human menstrual cycle. Am J Obstet Gynecol 1971; 109: 234-47.

14 Boardman P L, Hart F D. Clinical measurements of the antiinflammatory effects of salicylates in rheumatoid arthritis. $\mathrm{Br}$ Med J 1967; iv: 264-8.

15 Cove-Smith J R, Kabler P, Pownall R, Knapp M S. Circadian variation in an immune response in man. $\mathrm{Br}$ Med J 1978; ii: 253-4.

16 Fauci A S, Dale D C, Balow J E. Glucocortocoid therapy: mechanism of action and clinical considerations. Ann Intern Med 1976; 84: 304-15.

17 Pownall R, Knapp M S. Chromobiologic evaluation of hypersensitivity reactions and the influence of ciracadian variations of endogenous corticosteroid. Allergologie 1980; suppl 4: 231-6.

18 Halka J F, Omran K F. The uterine cervix as a potential local antibody secretor. Am J Obstet Gynecol 1969; 104: 440-2.

19 Wira C R, Sandoe C P. Sex steroid hormone regulation of IgA and IgG in rat uterine secretion. Nature 1977; 268: 534-5.

20 Mathur S, Rajesh S M, Goust J M, Oliver Williamson H, Fudenberg $\mathrm{H} \mathrm{H}$. Cyclic variations in white cell subpopulations in the human menstrual cycle: correlations with progesterone and estradial. Clin Immunol Immunopathl 1979; 13: 246-53.

21 Persellin $\mathbf{R} \mathbf{H}$. Inhibitions of inflammatory and immune responses in pregnancy serum. Clin Rheum Dis 1981; 7: 769-80.

22 Wyle F A, Kent J R. Immunosuppression by sex steroid hormones 1 . The effect upon PHA and PPD stimulated lymphocytes. Clin Exp Immunol 1977; 27: 407-15.

23 Bodel P, Dillard G M, Kaplan S S, Malawista S E. Antiinflammatory effects of estradiol on human blood leukocytes. J Lab Clin Med 1972; 80: 373-84.

24 Dawker M G. Serum levels of P.Z.P. during the normal menstrual cycle. Acta Obstet Gynecol Scand 1976; 55: 467-8. 